\title{
Large Arteriovenous Malformation Associated with Persistent Primitive Hypoglossal Artery \\ -Case Report-
}

\author{
Yasushi SHIBATA, Akio HYodo, Atsushi SAITo, \\ Yoshihiko YOSHII and Tadao NOSE \\ Department of Neurosurgery, Institute of Clinical Medicine, \\ University of Tsukuba, Tsukuba, Ibaraki
}

\begin{abstract}
A rare case of large arteriovenous malformation (AVM) with persistent primitive hypoglossal artery in a 43-year-old male was treated by staged embolization, followed by total removal. AVM associated with carotid-basilar anastomosis is quite rare, but the incidence of AVM in patients with carotid-basilar anastomosis is high. AVM associated with persistent carotid-basilar anastomosis has no distinguishing features compared with ordinary AVM, but participation of the posterior circulation as a feeder is characteristic.
\end{abstract}

Key words: arteriovenous malformation, carotid-basilar anastomosis, persistent primitive hypoglossal artery, embolization

\section{Introduction}

Primitive hypoglossal artery (PHA) is a rarely occurring persistent embryonal artery possibly associated with vascular anomalies such as aneurysm and arteriovenous malformation (AVM)." Here we describe a case of a large AVM associated with persistent PHA, treated by staged embolization and total removal. We discuss reported cases of AVM with persistent carotid-basilar anastomosis, and the possible causes of the association.

\section{Case Report}

A 43-year-old male suffered sudden onset of a severe headache with nausea in the early morning of April 5, 1989. Computed tomographic (CT) scans on admission to another hospital suggested a large AVM in the left occipital region, but no obvious intracranial hemorrhage. However, the clinical symptom strongly suggested slight subarachnoid hemorrhage. He was transferred to our hospital for examination of the intracranial lesion on May 18, 1989.

Received December 11, 1990; Accepted May 27,

On admission, neurological and physical examinations were normal except for cranial vascular bruit. CT scanning and magnetic resonance (MR) imaging demonstrated a large cerebral AVM, about $6 \mathrm{~cm}$ in diameter, located mainly in the left occipital lobe and extending into the temporoparietal region (Figs. 1 and 2). Cerebral angiography revealed a large AVM fed by the left middle cerebral, posterior cerebral, occipital, and meningeal arteries, and
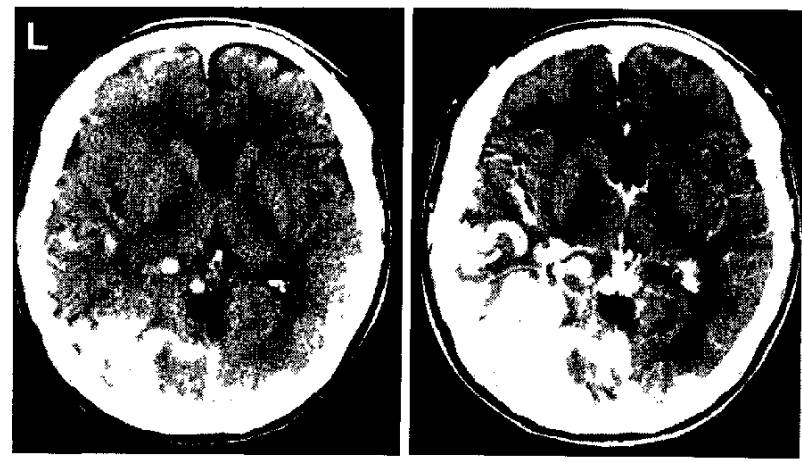

Fig. 1 Pre- (left) and postcontrast (right) $\mathrm{CT}$ scans demonstrating a large vascular mass, about 6 $\mathrm{cm}$ in diameter, in the left occipital lobe. 


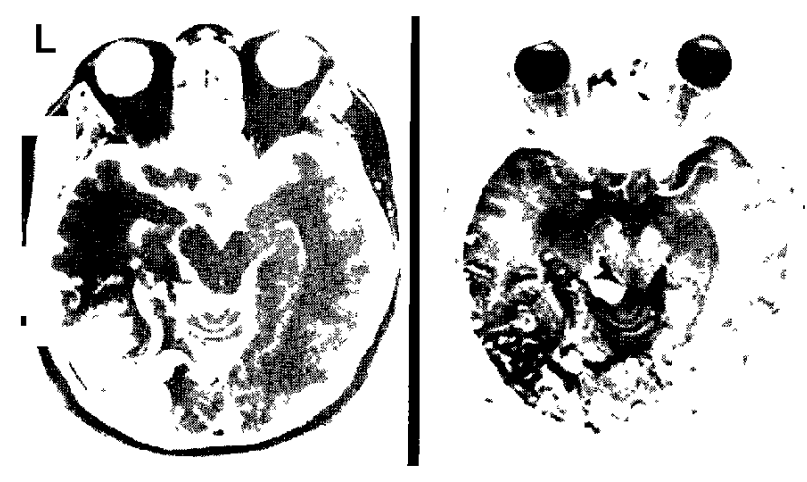

Fig. $2 \mathrm{~T}_{1^{-}}$(left: TR/TE $\left.600 / 20 \mathrm{msec}\right)$ and $\mathrm{T}_{2}$-weighted (right: TR/TE $2500 / 80 \mathrm{msec}$ ) axial MR images showing the left occipital lesion as flow void.

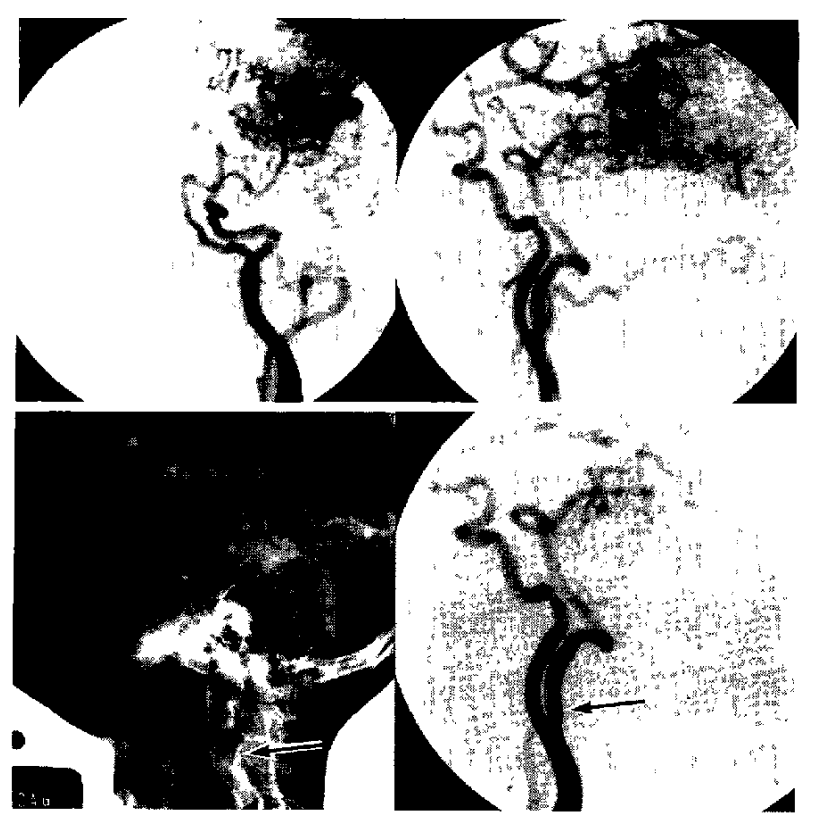

Fig. 3 upper: Left carotid angiograms, anteroposterior (left) and lateral (right) views, showing the left occipital AVM fed by the left middle cerebral, posterior cerebral, occipital, and meningeal arteries. lower: Left internal carotid angiograms, lateral views, revealing the primitive hypoglossal artery (arrow) arising from the internal carotid artery at the $\mathrm{C} 2$ level.

drained mainly by the superficial cortical veins and a deep vein (Fig. 3 upper). Left internal carotid angiography demonstrated left PHA originating from the left internal carotid artery at the $C 2$ level and ending at the distal left vertebral artery (Fig. 3 lower). The AVM was located distally to the left PHA.

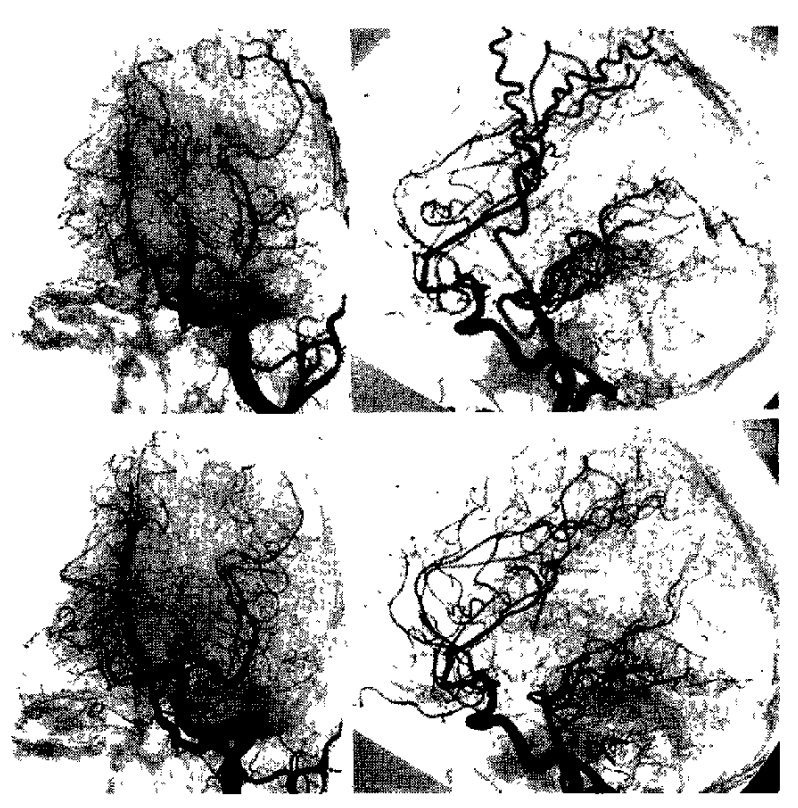

Fig. 4 Left carotid angiograms, anteroposterior (left) and lateral (right) views. upper: Angiograms after embolization showing about $90 \%$ of the initial AVM is embolized. lower: Angiograms after operation disclosing total removal of the AVM.

The AVM was embolized preoperatively because of the size and high flow. Ethylenevinyl alcohol and polyvinyl alcohol particles were infused transfemorally through a Tracker-18 infusion catheter (Target Therapeutics, San Jose, Cal., U.S.A.) and a leak balloon catheter (Dow Corning, Kanagawa). The procedure was repeated four times between June 7 and July 10 under local anesthesia with neurological examination and electroencephalographic monitoring. Superselective cannulation to the left posterior cerebral artery was performed via the left PHA. Right homonymous hemianopsia and temporally mild dyscalculia occurred after embolization. Cerebral angiography showed that about $90 \%$ of the initial AVM was embolized (Fig. 4 upper). The AVM was totally removed with relatively little bleeding on July $12,1989$.

Mild dyscalculia and dysgraphia appeared postoperatively. The right homonymous hemianopsia remained unchanged. Postoperative cerebral angiography confirmed the total removal of the AVM (Fig. 4 lower). His neurological deficits improved gradually. He was discharged on August 3, 1989, and resumed work as a farmer. 
Table 1 Summary of reported cases of AVM with carotid-basilar anastomosis

\begin{tabular}{|c|c|c|c|c|c|c|c|}
\hline Author (Year) & $\begin{array}{l}\text { Age, } \\
\text { Sex }\end{array}$ & $\begin{array}{l}\text { Embryonal } \\
\text { artery }\end{array}$ & Site of $A V M$ & $\begin{array}{l}\text { Main } \\
\text { feeder }\end{array}$ & $\begin{array}{l}\text { Participation } \\
\text { of posterior } \\
\text { circulation }\end{array}$ & Symptom & Therapy \\
\hline $\begin{array}{l}\text { Krayenbühl and Yasargil } \\
(1957)^{13 j}\end{array}$ & $48, \mathrm{M}$ & rt PTA & rt cerebellum & VA & + & $\begin{array}{l}\text { neuralgia, } \\
\text { vertigo }\end{array}$ & \\
\hline Schiefer and Walter (1959) & $51, \mathrm{M}$ & PTA & lt $\mathrm{P}$ & & & bleeding & extirpation \\
\hline Weickmann $(1959)^{277}$ & $18, \mathrm{~F}$ & rt PTA & It cerebellum & VA & + & bleeding & extirpation \\
\hline Campbell and Dyken $\left.(1961)^{2}\right)$ & $38, \mathrm{~F}$ & rt PTA & It TP & $\mathrm{MCA}$ & - & epilepsy & \\
\hline Lamb and Morris $(1961)^{14)}$ & $23, \mathrm{~F}$ & lt PTA & It $\mathrm{O}$ & MCA, PCA & + & bleeding & extirpation \\
\hline Gannon $(1962)^{81}$ & $46, F$ & it PTA & rt PO & & & bleeding & extirpation \\
\hline Frugoni et al. $(1963)^{71}$ & $18, \mathrm{M}$ & rt PTA & rt PO & $\mathrm{MCA}, \mathrm{PCA}$ & + & bleeding & \\
\hline Eadie et al. $(1964)^{37}$ & $\begin{array}{l}? \\
?\end{array}$ & $\begin{array}{l}\text { PTA } \\
\text { PTA }\end{array}$ & & & & $\begin{array}{l}\text { bleeding } \\
\text { epilepsy }\end{array}$ & \\
\hline Endo et al. $(1965)^{4)}$ & ? & rt PTA & infratentorial & VA & + & & $\begin{array}{l}\text { rt carotid } \\
\text { ligation }\end{array}$ \\
\hline Perret and Nishioka $(1966)^{191}$ & $?$ & rt PTA & rt pons & PTA & + & bleeding & $\begin{array}{l}\text { it carotid } \\
\text { trapping }\end{array}$ \\
\hline Fields $(1968)^{6 !}$ & $25, \mathbf{F}$ & It PTA & rt $\mathrm{PO}$ & MCA & - & bleeding & \\
\hline Moody and Poppen $(1970)^{173}$ & $?$ & PTA & & PTA & + & & \\
\hline Karasawa et al. $(1972)^{12)}$ & $28, \mathrm{~F}$ & $\begin{array}{l}\text { It POA, } \\
\text { rt PTA }\end{array}$ & $\begin{array}{l}\text { great vein } \\
\text { of Galen }\end{array}$ & PCA & + & bleeding & \\
\hline Karasawa et al. $(1973)^{11 !}$ & $9, \mathrm{M}$ & rt PHA & rt $P$ & $\mathrm{ACA}, \mathrm{MCA}$ & - & bleeding & $\begin{array}{l}\text { preoperative } \\
\text { death }\end{array}$ \\
\hline Yamauchi et al. (1974) $)^{29)}$ & $51, \mathrm{M}$ & It PHA & rt P & $\mathrm{ACA}$ & - & bleeding & \\
\hline Ferrante and Lorenzo $(1976)^{51}$ & $28, \mathrm{M}$ & lt PTA & rt PO & & & epilepsy & \\
\hline Jayaraman el al. $(1977)^{10)}$ & $27, \mathrm{~F}$ & It PTA & It $T$ & MCA, PCA & + & bleeding & conservative \\
\hline Tomsick et al. $(1979)^{241}$ & $17, \mathrm{M}$ & $\begin{array}{l}\text { It PTA } \\
\text { rt PTA, } \\
\text { rt POA }\end{array}$ & $\begin{array}{l}\mathrm{rt} T \\
\mathrm{rt} T\end{array}$ & $\begin{array}{l}\text { MCA } \\
\text { MCA, PCA }\end{array}$ & $\overline{+}$ & $\begin{array}{l}\text { bleeding } \\
\text { epilepsy }\end{array}$ & \\
\hline Agnoli $(1982)^{1)}$ & $43, \mathrm{M}$ & rt PTA & $\mathrm{rtO}$ & PCA & + & epilepsy & \\
\hline Wakai et al. $(1987)^{261}$ & $20, \mathrm{~F}$ & rt PTA & rt $\mathrm{PO}$ & & & bleeding & extirpation \\
\hline Sahoo et al. $(1988)^{201}$ & $2, \mathrm{M}$ & rt PHA & rt $\mathrm{O}$ & $\mathrm{ECA}, \mathrm{PHA}$ & + & epilepsy & feeder ligation \\
\hline Uchino et al. $(1989)^{25)}$ & $16, \mathrm{~F}$ & lt PTA & corpus callosum & $\mathrm{ACA}, \mathrm{PCA}$ & + & bleeding & irradiation \\
\hline Mercado et al. $(1990)^{16)}$ & $30, \mathrm{~F}$ & It PHA & lt $\mathrm{P}$ & $\mathrm{MCA}, \mathrm{AChA}$ & - & bleeding & extirpation \\
\hline Yamanaka et al. $(1990)^{28)}$ & $46, \mathrm{M}$ & lt PHA & It cerebellum & PICA, SCA & + & bleeding & extirpation \\
\hline Present case & $43, \mathrm{M}$ & lt PHA & lt $\mathrm{O}$ & $\mathrm{MCA}, \mathrm{PCA}$ & + & bleeding (?) & $\begin{array}{c}\text { embolization and } \\
\text { extirpation }\end{array}$ \\
\hline
\end{tabular}

ACA: anterior cerebral artery, AChA: anterior choroidal artery, ECA: external carotid artery, MCA: middle cerebral artery, O: occipital lobe, P: parietal lobe, PCA: posterior cerebral artery, PHA: primitive hypoglossal artery, PICA: posterior inferior cerebellar artery, PO: parieto-occipital lobe, POA: primitive otic artery, SCA: superior cerebellar artery, T: temporal lobe, TP: temporoparietal lobe, VA: vertebral artery.

\section{Discussion}

Krayenbühl and Yasargil ${ }^{13)}$ reported the first case of AVM associated with persistent primitive trigeminal artery in 1957. Since then only 27 cases of AVM with carotid-basilar anastomosis have been reported (Table 1). ${ }^{1-8,10-14,16,17,19-21,24-29)}$ There was no significant sex predominance. The age at diagnosis ranged from 2 to 51 years old, but mainly between 20 and 40 years old. AVMs with carotid-basilar anastomosis vary in location, and are distributed similarly to general AVMs. The AVM was ipsilateral to the carotidbasilar anastomosis in slightly more cases than contralateral. Twenty-one of 27 cases included a feeding artery, and 15 of these cases had posterior circulation participation. The most frequent clinical manifestation was intracranial hemorrhage.

Carotid-basilar anastomosis is frequently associated with aneurysm. ${ }^{1,14)}$ However, the significance of AVM associated with carotid-basilar anastomosis is controversial. Some authors consider it to be a chance one only, ${ }^{3,6)}$ but Wakai et al. ${ }^{26)}$ showed a statistically higher incidence of vascular anomalies, i.e., AVM and aneurysm, in patients with primitive trigeminal artery than in the general population. ${ }^{15}$ )

An AVM probably originates at the second stage of Streeter when the primordial blood vessel plexus resolves into veins, arteries, and capillaries., ${ }^{9,18,231}$ The vertebrobasilar system and posterior communicating artery finish development and the primitive carotidbasilar anastomosis regresses and disappears at the fifth stage. ${ }^{7,23)}$ Any effect of an AVM on the per- 
sistence of the carotid-basilar anastomosis is unknown. However, an AVM may disturb the regression of the carotid-basilar anastomosis because the AVM requires a high blood flow. In our case, the coexistence of the AVM and the carotid-basilar anastomosis may have been associated, because the AVM was distal to the PHA. Seventy-one percent of such AVMs associated with carotid-basilar anastomosis were fed by the posterior circulation, a greater incidence than among general AVMs, which supports this hypothesis.

Our case was successfully treated with staged embolization followed by total removal. A large AVM has an especially high risk of normal perfusion pressure breakthrough (NPPB) following total removal or sudden embolization of feeders. Staged embolization followed by removal gradually changed the cerebral hemodynamics avoiding NPPB. Extensive AVM embolization assisted surgical removal by reducing intraoperative bleeding which may limit total excision. ${ }^{22)}$

\section{References}

1) Agnoli AL: Vascular anomalies and subarachnoid haemorrhage associated with persisting embryonic vessels. Acta Neurochir (Wien) 60: 183-199, 1982

2) Campbell RL, Dyken ML: Four cases of carotidbasilar anastomosis associated with central nervous system dysfunction. J Neurol Neurosurg Psychiat 24: 250-253, 1961

3) Eadie MJ, Jamieson KG, Lennon EA: Persisting carotid-basilar anastomosis. J Neurol Sci 1: 501-511, 1964

4) Endo S, Akiba Y, Ogawa I, Endo K, Yamada T: Various features of primitive trigeminal artery especially a case associated with an infratentorial A-V fistula. Neurol Med Chir (Tokyo) 7: 219, 1965

5) Ferrante L, Lorenzo ND: Primitive trigeminal artery: Clinical and angiographic study. $J$ Neurosurg Sci 20: 321-326, 1976

6) Fields WS: The significance of persistent trigeminal artery: Carotid-basilar anastomosis. Radiology 91: 1096-1101, 1968

7) Frugoni P, Mingrino S, Giammusso V: Association of cerebral vascular malformations: Coexistence of arteriovenous angioma and persistent carotid-basilar anastomosis (primitive trigeminal artery). Neurochirurgie 6: 74-81, 1963

8) Gannon WE: Malformation of the brain: Persistent trigeminal artery and arteriovenous malformation. Arch Neurol (Chicago) 6: 496-498, 1962

9) Garretson HD: Intracranial arteriovenous malformations, in Wilkins RH, Rengachary SS (eds): Neurosurgery. New York, McGraw-Hill, 1985, pp 1448-1458

10) Jayaraman A, Garofalo M, Brinker RA, Chusid JG:
Cerebral arteriovenous malformation and the primitive trigeminal artery. Arch Neurol 34: 96-98, 1977

11) Karasawa J, Kikuchi H, Furuse S, Kawai S, Uchida Y, Sakaki T: Studies on 2 cases of a persistent primitive hypoglossal artery: Case reports on a 9year-old male patient with arteriovenous malformation and a 55-year-old male patient with brain stem syndrome. No To Shinkei 25: 1773-1779, 1973 (in Japanese)

12) Karasawa $J$, Terano $M$, Nishikawa $M$, Kyoi $K$, Kikuchi $\mathrm{H}$, Makita $\mathrm{Y}$, Matsumura $\mathrm{H}$ : A case of bilateral persistent carotid-basilar anastomoses (primitive otic artery and primitive trigeminal artery) with multiple cerebrovascular anomalies. No To Shinkei 24: 91-98, 1972 (in Japanese)

13) Krayenbühl H, Yasargil MG: Die Vaskulären Erkrankungen im Gebiet der Arteria Vertebralis und Arteria Basialis. Stuttgart, Georg Thieme, 1957, pp 136- 140

14) Lamb J, Morris L: The carotid-basilar artery: A report and discussion of five cases. Clin Radiol 12: 179-186, 1961

15) Luessenhop AJ: Natural history of cerebral arteriovenous malformations, in Wilson CB, Stein BM (eds): Intracerebral Arteriovenous Malformation. Baltimore, Williams \& Wilkins, 1984, pp 12-23

16) Mercado RG, Cavazos E, Urrutia G: Persistent hypoglossal artery in combination with multifocal arteriovenous malformations of the brain: Case report. Neurosurgery 26: 871-876, 1990

17) Moody RA, Poppen JL: Arteriovenous malformations. J Neurosurg 32: 503-511, 1970

18) Moore KL: The Developing Human: Clinically Oriented Embryology, ed 3. Philadelphia, WB Saunders, 1982, pp 63-64

19) Perret G, Nishioka H: Arteriovenous malformations: An analysis of 545 cases of cranio-cerebral arteriovenous malformations and fistulae reported to the cooperative study. $J$ Neurosurg 25: 467-490, 1966

20) Sahoo Y, Mathai KV, Mallikarjunaiah GS, David BS, Parida S: Persistent hypoglossal artery. Indian Journal of Radiology and Imaging 42: 144-146, 1988

21) Schiefer W, Walter W: Die Persistenz Embryonaler Gefässe als Ursache von Blutungen des Hirns und seiner Häute. Acta Neurochir (Wien) 7: 53-65, 1959

22) Spetzler RF, Martin NA, Carter LP, Flom RA, Raudzens PA, Wilkinson E: Surgical management of large AVM's by staged embolization and operative excision. $J$ Neurosurg 67: 17-28, 1987

23) Streeter GL: The developmental alterations in the vascular system of the brain. Contributions to Embryology 8: 5-38, 1918

24) Tomsick TA, Lukin RR, Chambers AA: Persistent trigeminal artery: Unusual associated abnormalities. Neuroradiology 17: 253-257, 1979

25) Uchino A, Matsunaga M, Ohno M: Arteriovenous malformation of the corpus collosum associated with persistent primitive trigeminal artery: Case report. 
Neurol Med Chir (Tokyo) 29: 429-432, 1989

26) Wakai S, Ueda Y, Nagai M: Cerebrovascular anomalies associated with primitive trigeminal artery: Report of three cases. Neurol Med Chir (Tokyo) 27: 633-636, 1987

27) Weickmann F: Die Zerebralen Durchblutungsstorungen des Erwachsenenalters, Zweite Auflage. Volk und Gesundheit, 1959, 464 pp

28) Yamanaka $K$, Noguchi $K$, Hayasaki K, Matsuoka $Y$ : Persistent primitive hypoglossal artery associated with arteriovenous malformation: Case report. Neurol Med Chir (Tokyo) 30: 949-955, 1990
29) Yamauchi $Y$, Aoyama $T$, Sugitani $Y$, Kohama $M$, Nukada $T$ : A case of persistent hypoglossal artery associated with arteriovenous malformation and a study of the cerebral circulation of the case. Rinsho Shinkeigaku 14: 539-547, 1974 (in Japanese)

Address reprint requests to: A. Hyodo, M.D., Department of Neurosurgery, Institute of Clinical Medicine, University of Tsukuba, 1-1-1 Tennodai, Tsukuba, Ibaraki 305, Japan. 